\title{
Expondo os desafios do mundo à Igreja: a linguagem visual de vanguarda da revista Cruz de Malta de 1962
}

\author{
Exhibiting world's challenges to the church: \\ the vanguard visual language of the magazine \\ Cruz de Malta of 1962
}

\section{Expondo los desafíos del mundo para la Iglesia: el lengua visual vanguardia de la revista Cruz de Malta de 1962}

\author{
Helmut Renders*
}

\begin{abstract}
RESUMO
Este artigo descreve e analisa as mudanças da linguagem visual religiosa da revista Cruz de Malta Marcha no ano 1962 que surgem junto com um novo lema da revista, "Juventude em luta para um mundo melhor". Como base se comparou capas dos anos 1960, 1961, 1962, 1963 e 1964 e alguns exemplos do uso do desenho gráfico nas edições da revista de 1962. Percebe-se como a tentativa de estender as fronteiras da atuação da igreja incluindo um diálogo sobre os problemas mais urgentes globais e nacionais da época rompe com padrões da cultura visual que antecipam os anos 70 e 80 por um breve momento. O rápido desaparecimento dessa linguagem religiosa visual vanguarda depois um ano parece hoje como antecipação ou pré-anúncio dos eventos que acabam preparando a ditatura militar brasileira de 1964 .

Palavras-chave: Linguagens religiosas; cultura visual evangélica; revista Cruz de Malta; juventude evangélica; década 60 .
\end{abstract}

\begin{abstract}
This article describes and analyzes the changes of the religious visual language of the magazine Cruz de Malta in the year 1962 that appear alongside with a new motto of the magazine, "Youth in struggle for a better world". As a basis we compared covers from the 1960s, 1961, 1962, 1963 and 1964 and some examples of the use of graphic design in the 1962 issue of the magazine. It is perceived as the attempt to extend the boundaries of church performance including a dialogue on the more urgent global and national issues of the time break with visual culture standards that anticipate the $70 \mathrm{~s}$ and $80 \mathrm{~s}$ for a brief moment. The rapid disappearance of this avant-garde visual religious language after one year seems today as an anticipation or pre-announcement of the events that ended up preparing the Brazilian military dictatorship of 1964.
\end{abstract}

Keywords: Religious languages; visual evangelical culture; magazine Cruz de Malta; evangelical youth; 1960 s.

* Professor doutor da Faculdade de Teologia, professor titular e coordenador do Programa de Pós-Graduação em Ciências da Religião da Universidade Metodista de São Paulo.

E-mail: helmut.renders@metodista.br 


\begin{abstract}
RESUMEN
Este artículo describe y analiza los cambios del lenguaje visual religioso de la revista Cruz de Malta en el año 1962 que surgen junto con un nuevo lema de la revista, "Juventud en lucha para un mundo mejor". Como base se comparó las capas de los años 1960, 1961, 1962, 1963 y 1964 y algunos ejemplos del uso del diseño gráfico en las ediciones de la revista de 1962. Se percibe como el intento de extender las fronteras de la actuación de la iglesia incluyendo un diálogo sobre los los problemas más urgentes globales y nacionales de la época rompe con patrones de la cultura visual que anticipan los años 70 y 80 por un breve momento. La rápida desaparición de ese lenguaje religioso visual vanguardia después de un año parece hoy como anticipación o pre-anuncio de los eventos que acaban preparando la dictadura militar brasileña de 1964.

Palabras clave: Lenguajes religiosos; cultura visual evangélica; revista Cruz de Malta; juventud evangélica; década 60.
\end{abstract}

\title{
Introdução
}

A cultura visual evangélica brasileira se construiu e constrói, desconstruiu e desconstrói, ao longo do século vinte não de forma linear, mas, com saltos, recuos e voltas, e por meio de vertentes distintas que apresentam seus projetos e suas convicções visuais paralelamente. ${ }^{1} \mathrm{O}$ texto em seguida foca num único ano, o ano de 1962, e um grupo específico e restrito, um grupo da juventude evangélica, no caso mais específica, da juventude metodista. Esse grupo procurou visualizar e expor a sua cosmovisão por meio da sua revista Em Marcha aos seus pares mais imediatos e às suas igrejas. Para isso, eles recorreram a uma linguagem visual novo, inédita, nunca vista anteriormente nas revistas religiosas do país. E mesmo isso ocorreu somente em um período breve de 12 meses, e que terminou tão abrupto com a saída da equipe responsável como tinha iniciada com a sua chegada, anteciparam uma linguagem visual que ia retornar na década 70 e 80 entre os movimentos sociais, razão que nos referimo-nos no título a uma linguagem visual vanguarda.

O ano de 1962 era um ano de grandes perspectivas das Igrejas Evangélicas Brasileiras organizadas na então Confederação Evangélica do Brasil ou CEB. Todos/as estavam olhando para a cidade de Recife, onde o Departamento Social da CEB estava organizando um congresso para tratar especificamente de assuntos sociais do Nordeste. Nessa conferencia, um dos convidados preletores, Gilberto Freire, refletia sobre a presença cultural do protestantismo brasileiro e resumiu a sua percepção com as seguintes palavras:

A despeito do crescente número de cristãos evangélicos em nosso país, ainda não apareceu o brasileiro de gênio, que nascido evangélico, criado em meio evangélico, identificado com a interpretação evangélica da vida e da cultura brasileira, se afirmasse no Brasil grande poeta ou grande escritor em língua portuguesa, ou compusesse música brasileira,

1 Quanto as grandes tendências da cultura visual evangélica brasileira, veja a primeira proposta da sua periodização em Helmut Renders (2018, p. 10-37). 
marcada por esta interpretação ou por esta inspiração, ou o arquiteto também de gênio que desenvolvesse para as igrejas evangélicas do trópico, um tipo de arquitetura que não fosse nem a imitação do tipo católico, nem reprodução do protestante anglo-saxônico ou germânico (FREIRE, 1963, p. 59-60).

Ao final da sua análise, Freire desafiou os representantes das igrejas históricas presentes com as seguintes palavras:

É tempo de o cristianismo brasileiro evangélico ir além e concorrer para esse enriquecimento com um escritor do porte e da flama revolucionária, eu diria, de Euclides da Cunha; com um poeta da grandeza de Manoel Bandeira; com um compositor que seja outro Villa-Lobos, que componha baquianas brasileiras que sejam interpretação ao mesmo tempo evangélica e brasileira de Bach. Também um caricaturista ou um teatrólogo revolucionariamente evangélico que pela caricatura ou pelo teatro denuncie abusos de ricos que para conservarem um privilégio de classe pretendam se fazer passar por defensores ou conservadores de tradições religiosas ou mesmo do que se intitula às vezes, pomposa e hipocritamente, civilização cristã (FREIRE, 1963, p. 62).

Em seguida pretendemos demonstrar, que a juventude dessas igrejas, não somente simpatizava em parte com as observações de Freire e o mea culpa dos seus líderes religiosos articulada na próxima citação, mas, antecipou as conclusões da Conferência do Nordeste, e demonstrou uma visão em sintonia com a percepção do mundo de Gilberto Freire, da necessidade de encarar os desafios de uma nova fronteira cultural:

Perguntamos até que ponto a Igreja Evangélica tem penetrado a nossa cultura autêntica, ou se identificado com ela; e até onde se tem sobreposto artificialmente a ela, ou se colocado ao lado dela, criando assim uma espécie de "subcultura da Igreja", que não tem raízes na tradição cultural brasileira, nem terá futuro nela. [...] Não é preciso rejeitar totalmente as contribuições estrangeiras, naquilo que elas têm de valor para enriquecer a condição brasileira. É, porém, necessário abrasileirá-las. É na sua particularidade e identificação com o povo que uma obra artística ou outra instituição cultural podem atingir e manifestar valores universais que contribuem para a verdadeira humanização do homem, manifestada na encarnação de Jesus Cristo (S.N., 1963, p. 182). ${ }^{2}$

É a nossa hipótese de trabalho que a juventude protestante nesse momento, se sentia desafiada, não apenas pela fronteira cultural, mas também pela fronteira social. Para demostrar isso, iremos apresentar e interpretar capas da revista da juventude metodista "Cruz de Malta”. Na então Igreja Metodista

2 Uma passagem mais extensa aparece ainda no Expositor Cristão (15/04/1963, p. 3) sob o título: "Gilberto Freire fala aos evangélicos". A discussão ficou, então, não somente em nível de congresso, mas foi levada às igrejas locais. 
do Brasil que se renomeou em 1971 como Igreja Metodista, duas associações de grupos societários tinham as suas próprias revistas: a sociedade das mulheres metodistas possuía a revista "Voz Missionária" e a sociedade dos jovens metodistas detinha a revista "Cruz de Malta". "Próprias revistas" se refere a uma ampla responsabilidade para com os conteúdos, o formato, e financeiras, mediante a venda das mesmas. Ambas as revistas tinham redações compostas pelos seus pares, que cuidavam também das escolhas da arte gráfica.

\section{As capas da revista "Cruz de Malta": de uma linguagem religiosa visual moderna para uma linguagem de vanguarda}

Em janeiro 1962 um novo grupo redacional com representações do sul, centro e sudeste do País assumiu a Revista Cruz de Malta. Além do pastor responsável, "Dico" William R. Schisler Filho ${ }^{3}$ participaram Caio Navarro de Toledo ${ }^{4}$, Ulysses Telles Guariba Neto ${ }^{5}$ (1940-1971), Heleny Telles Ferreira Guariba (1941-1971[?] $)^{6}$, sua esposa ${ }^{7}$, Claudius Ceccon ${ }^{8}$ (1937-), Derly Marques $^{9}$ (1934-) e Derli Barroso (1938-) ${ }^{10}$, responsável pelo projeto gráfico. ${ }^{11} \mathrm{Um}$ pouco mais tarde, se juntou também Ondina Godoy Germano. Colaboradores da revista eram na época pessoas como os pastores presbiterianos João Dias

Pastor William R. Schisler Filho foi quem cuidou do grupo dos jovens na época em que deixou São Paulo em 1976 e iniciou uma missão pioneira em Florianópolis, SC. Além de fundar a igreja metodista na cidade, criou um lar de idosos, o Centro Vivencial para Pessoas Idosas.

4 Aposentou-se como professor do Instituto de Filosofia e Ciências Humanas, Departamento de Ciência Política da UNICAMP com foco em ideologias e o golpe militar de 1964 (TOLEDO, 2014, 1984).

5 Aposentou-se como professor do Departamento de História da Faculdade de Filosofia, Letras e Ciências Humanas da USP.

6 Heleny Guariba, desaparecida desde 1971, é hoje, lembrada pelas suas contribuições para o teatro popular. Receberam seu nome o Teatro Studio Heleny Guariba em São Paulo, o Auditório Heleny Guariba do Teatro de Santo André, SP, e o Centro Cultural Heleny Guariba em Diadema, SP.

Se casaram em 1962. Depois da separação em 1969, Heleny militou com a guerrilha contra a ditadura.

8 Trabalhou como caricaturista para o Jornal do Brasil (1957ss), Pif Paf e O Pasquim. Depois ser preso por uma charge na revista O Pasquim, exilou-se em 1970 em Genebra e fundou, com Paulo Freire o Instituto de Ação Cultural (IDAC), no qual ele trabalhou em projetos de alfabetização na África lusófona, em bairros da periferia de São Paulo com o arcebispo Dom Paulo Evaristo Arns (1978ss). Fundou em 1986, com Paulo Freire, o cineasta Eduardo Coutinho e a escritora Ana Maria Machado o Centro de Criação da Imagem Popular (CECIP). Confira Claudius (2018).

9 Especialmente conhecido como fotógrafo do teatro (1957ss) escreve também: "Anti-comunismo: na fonte de inspiração para pastores sem assunto" (MARQUES, 15/10/1962, p. 2).

10 Nasceu em Avanhandava, SP e se juntou à redação de Piracicaba, SP. Se exilou aos EUA, onde estudou fotografia. Tem hoje a cidadania estadunidense. Realiza exibições artísticas de fotografias desde 1971.

11 Confira o impressum da Cruq de Malta, p. 3- (jan. / fev. 1962) e o Editorial de "Dico" (Pastor William R. Schisler Filho) na mesma página: "Gente nova tomou conta da "nossa" - e você vai gostar! Desde a Carochinha tem sido assim. Cada geração é bossa nova que tem o que dizer. E agora chegou a vez de Caio, Ulysses, Claudius, Heleny, Derly, Carmen - e você!” 
de Araújo ${ }^{12}$ (1930-2014) e [Millard] Richard Shaull, (1919-2002), (01/1961, p. $9-12$; 05-06/1962, p. 22-26 e 26-32) e os pastores metodistas Almir dos Santos (01-02/1960, p. 14-18) ${ }^{13}$ e Dorival Rodrigues Beulke (1927-2015) ${ }^{14}$.

As capas da Cruz de Malta eram inicialmente, "tradicionais". Em duas das revistas existe um "memorial visual" (figura 1 e 2) que abrangem capas dos anos 1936 até 1959. Um projeto gráfico não é perceptível. Existem capas com fotografias, desenhos, sumários, com ou sem informações a respeito da edição. Com a exceção da última, que representa um desenho, nenhuma delas mostra ambições artísticas.

Figura 1: Capas da revista Cruz de Malta dos anos 05/1936, 08/1937, 12/1938, 01/1939, 07 e $11 / 1945$, [194?], 09/1947 e [194?]

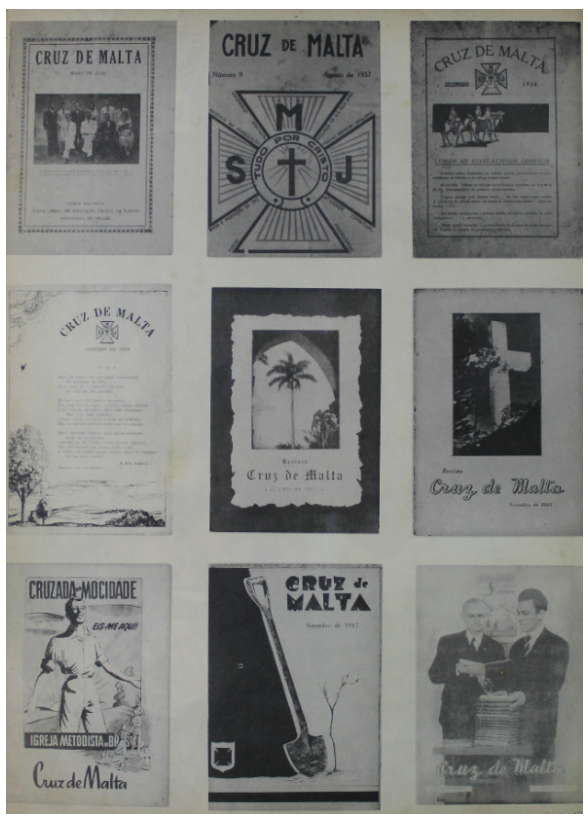

Fonte: CdM, ano 33, n. 1, janeiro 1960, p. 2
Figura 2: Capas da revista Cruz de Malta dos anos 12/1949, 05/1950, [195?], 07/1953, 02/1954, 07/1955, [195?], [195?] e [195?].

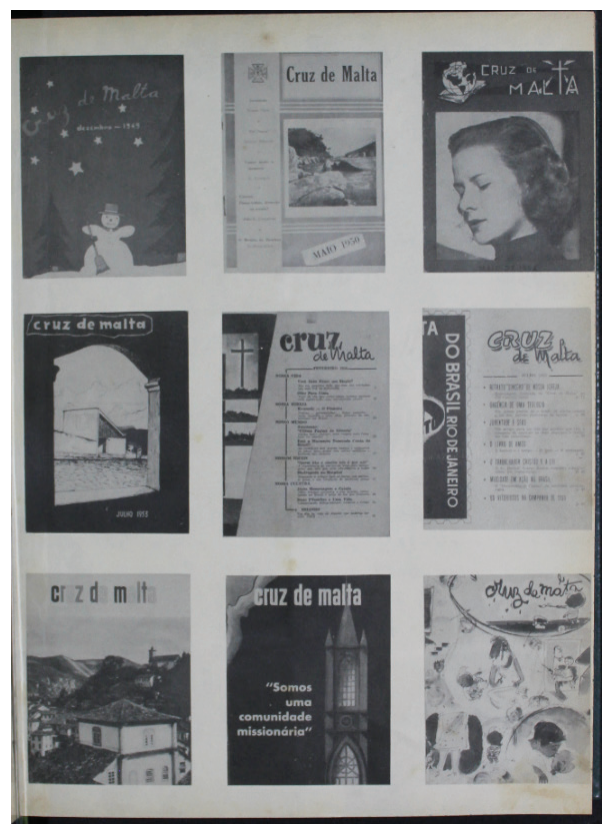

Fonte: CdM, ano, 32, n. 1, janeiro 1959, p. 2

$\mathrm{Na}$ década de 1960 (figura 3 e 4) assume-se um novo projeto gráfico, parecido com os de jornais ilustrados como Manchete ou O Cruzeiro desde

12 Além de análises, contribui com poesias (09-10/1962, p. 2) e letras de músicas ("Que Estou Fazendo Se Sou Cristão?”). No seu livro “Inquisição sem fogueiras” (2010) contou a história da perseguição da juventude presbiteriana durante a ditatura militar.

13 Pastor metodista e professor da Faculdade de Teologia para teologia prática. 1971 eleito bispo em Rio de Janeiro. Junto com Carlos Cunha, Waldo César responsável para a Conferência do Nordeste em 1962.

14 Beulke era entre 1960 e 1964 pastor metodista em Recife. Seu boletim de igreja tinha o nome "O revolucionário". Duas meses foi preso durante o regime militar. 
a década de $1950^{15}$. Acompanhou-se o projeto gráfico de jornais ilustrados seculares, já "consagrados" por quase uma década. Mas, quanto à igreja, o passo para a inclusão de uma linguagem visual secular não foi pequeno e sinaliza que a juventude da igreja acompanhava atentamente o mundo ao seu redor. Entretanto, não se trata de simples retratos, mas, de motivos construídos. Na figura 4, por exemplo, a cantora vestida com uma túnica vermelha é posicionada em frente de flores brancas, com um fundo de uma cortina vermelha. Copos de leite são usados como flores ornamentais cuja cor representa pureza e paz, como os lírios na iconografia clássica. ${ }^{16}$ Essa composição não tem nenhuma tensão composicional interessante, mas, ela cita, de longe, retratos de santos ou santas com - muitas vezes, três - lírios brancos.

Figura 3: Capa da revista Cruz de Malta capa de janeiro 1960

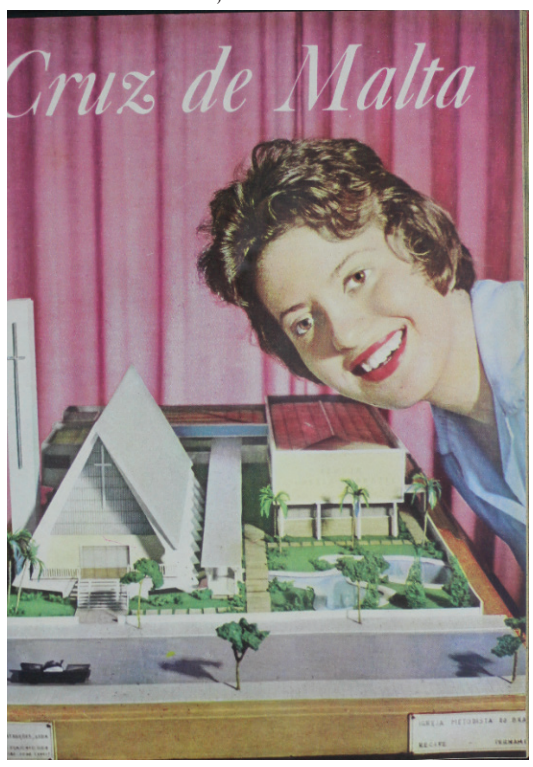

Fonte: CdM, ano 33, n. 1, janeiro 1960, capa
Figura 4: Capa da revista cruz de Malta, capa de novembro 1960

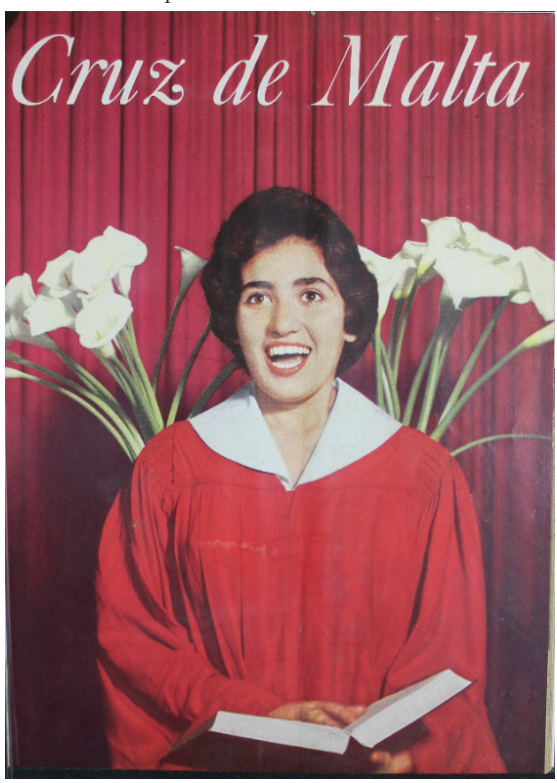

Fonte: CdM, ano 33, n. 11, nov. 1960, p. capa

Podemos resumir que com esse padrão de capa, a revista de juventude chegou em 1960, na contemporaneidade e o que hoje parece "retro" era na época algo moderno. Mas que mundo é esse? É um mundo religioso idealizado - copos de leite / lírios - onde se vive em função da religião, colaborando na construção de igrejas e cantando no coral.

15 Claudius Ceccon trabalhou a partir de 1954 na revista O Cruzeiro. Talvez trouxe ele essa linguagem visual para a revista Cruz de Malta.

16 Isso não define seu uso preferencial. No Brasil, a flor é a preferida para decorações de casamento. $\mathrm{Na}$ Alemanha, o uso dela é estritamente para velórios e funerais. 
Mas, em julho do próximo ano surgiu uma nova fase de ilustração, agora não somente preocupada com a capacidade de se comunicar para o mundo ao redor em uma linguagem conhecida. Agora se foca numa mensagem com uma nova linguagem. Essa narrativa visual nova, foi acompanhada por uma narrativa textual que, inicialmente, se encontrou na contracapa do caderno, sob o título "nossa capa".

Figura 5: Capa da revista Cruz de Malta de junho 1961

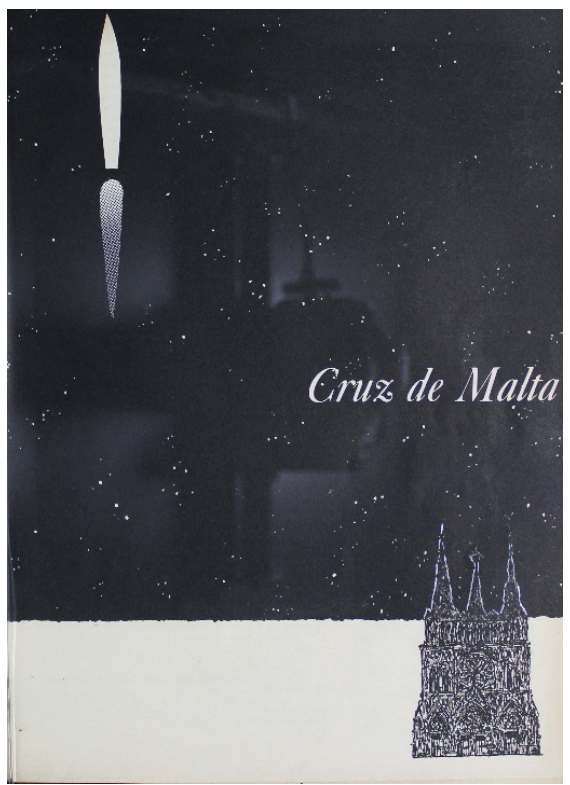

Fonte: CdM, ano 34, n. 6, junho 1961, p. capa
Figura 6: Capa da revista Cruz de Malta capa de julho 1961

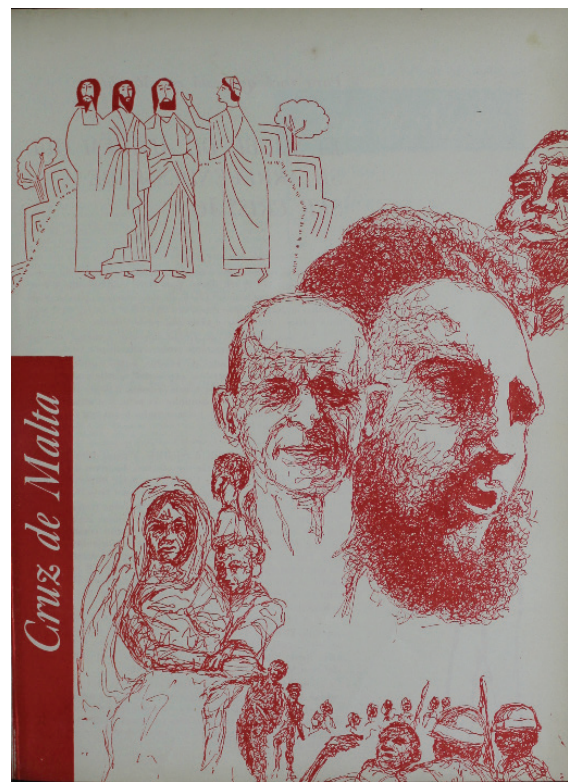

Fonte: CdM, ano 34, n. 7, julho 1961, p. capa

Emblemática é a explicação da capa de junho 1961, que retrata uma igreja acima de fundo branco e uma nave espacial decolando (figura 5):

Com o voo pioneiro de Gagarin o homem rompe a barreira do espaço cósmico. [...] O cristão não pode alhear-se a esse progresso científico, nem pode eximir-se de sua responsabilidade no mundo novo que surge com consequência desse fato. $\mathrm{O}$ desenho de "nosso" Claudius mostra-nos uma igreja, estilo gótico, mediévica, que apenas toca levemente com as suas torres a abóboda celeste [...] Qual o papel da Igreja, sua missão, sua razão de ser, seu modo de agir [...] Em um mundo que se transforma com rapidez supersônica não se pode mais caminhar com a velocidade de ontem. Quando nos sentamos num banco de igreja, ávidos para receber uma mensagem para o século XX, e ela nos chega com trajes do tempo de Império. [...]. Quando vemos a gente moça [...] tendo por motivo máximo de suas reuniões uma discussão a respeito se deve fazer um piquenique [...] \Quando vemos coisas como tais sem que ninguém se preocupe em 
ouvir os gritos de justiça que ecoam de todos os lados, em Cuba, no nosso paupérrimo nordeste, no convulsionado Congo, na Argélia, no Laos, nas favelas aqui perto, nas ruas de nossa cidade ... (CdM, ano 34, n. 6, junho 1961, p. 2).

Nessa passagem introdutória apresenta a redação da revista o programa que daqui para frente será traduzido em uma nova linguagem visual: "juventude em luta para um mundo melhor", o subtítulo da revista Cruz de Malta a partir de $1962^{17}$. As capas reposicionam o/a leitor/a: deve-se caminhar não de costas para o mundo, olhando para seus pares ou a igreja, mas, de olho ao mundo, encarando as suas realidades. Somente assim conquista-se o céu. Já a capa do próximo mês, julho 1961 (figura 6) retrata o mundo real, composto por militares e cíveis, uma mãe com criança no colo, Gandhi e Fidel Castro e uma pessoa negra, eventualmente, Martin Luther King Jr. Em um forte contraste com esses retratos, veja-se na parte superior esquerda um grupo de filósofos discutindo, mas, não se envolvendo, distante do mundo. Modelo de igreja que essa juventude quer superar e deixar atrás.

Figura 8: Capa da revista Cruz de Malta de

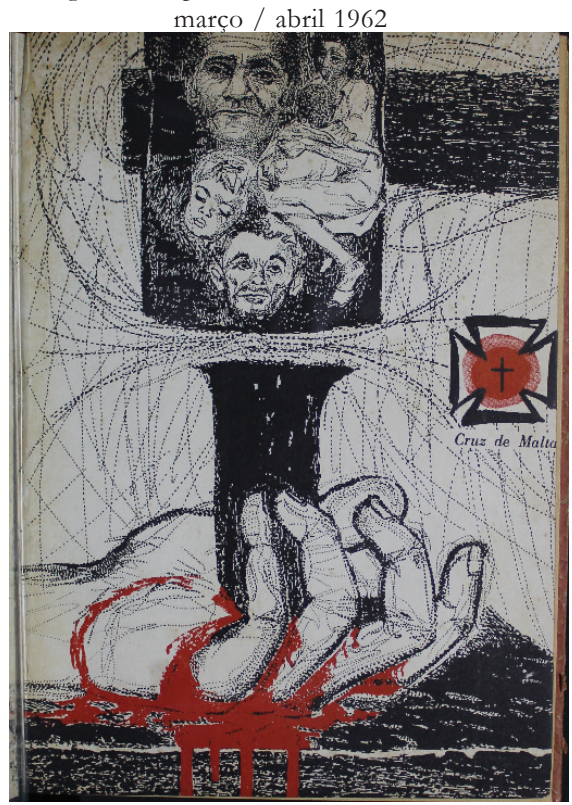

Fonte: Cruz de Malta, ano 35, n. 1, jan.- fev. 1962, capa
Figura 7: Capa da revista cruz de Malta , capa de janeiro / fevereiro 1962

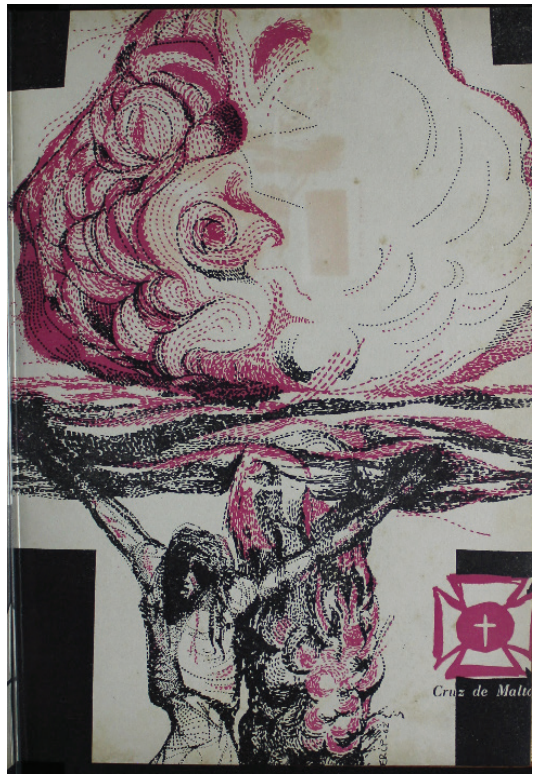

Fonte: Cruz de Malta, ano 35, n. 2, mar. - abr. 1962, capa

17 E até junho 1964, com interrupção durante todo ano 1963. O desparecimento coincide com a saída de Caio Toledo da redação da revista. 
As próximas duas capas (figuras 7 e 8) introduzem o tema da crucificação de Jesus Cristo e relacionam sua crucificação com os temas do sofrimento do povo (figura 7) e da ameaça da extinção humana por uma guerra com armas nucleares (figura 8). Toma-se na primeira das duas capas uma posição dentro da sociedade. Trata-se de uma postura a favor do povo indefeso, representado, por uma idosa, uma mulher com uma criança no colo - um motivo já repetido - e um casal de jovens. Seus retratos cabem num martelo que é usado para pregar uma mão com um prego numa tábua. O desenho vincula o sofrimento da crucificação diretamente com o sofrimento do povo. É a revolta de Cristo contra o sofrimento do povo que faz as autoridades o crucificarem; é a solidariedade de Cristo com o povo "até a morte na cruz" que demonstra que Deus não abandonou a terra, nem o povo sofrido. A capa da edição de março / abril continua nessa leitura da crucificação.

Figura 9: Capa da Revista cruz de Malta , capa de julho / agosto 1962

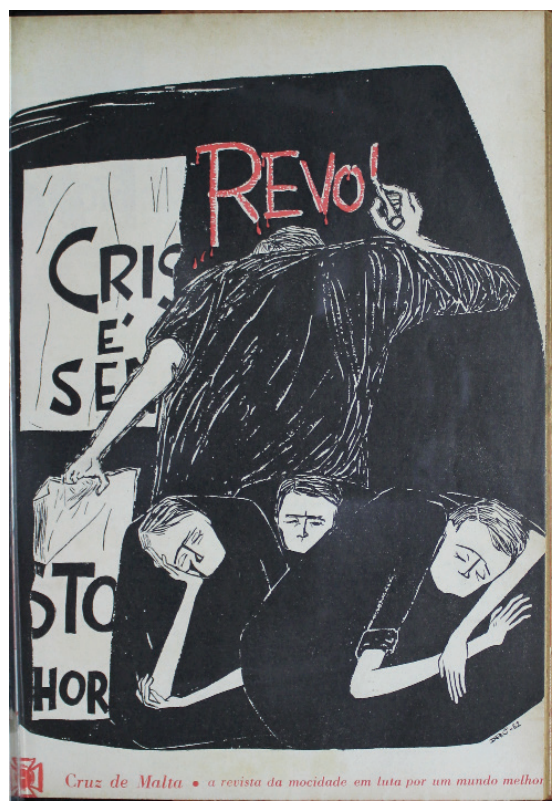

Cruz de Malta, ano 35, n. 4, jul.-aug. 1962, p. capa
Figura 10: Capa da revista Cruz de Malta de março / abril 1962, p. 14

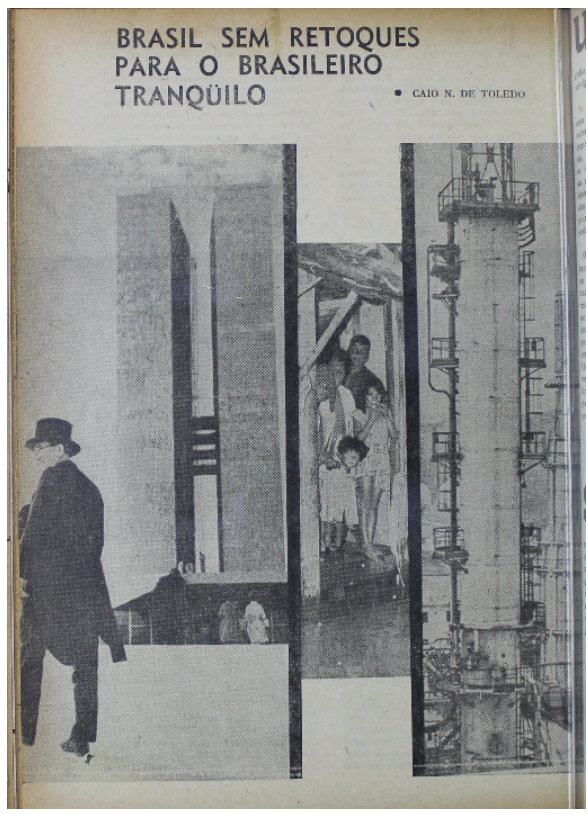

Cruz de Malta, ano 35, n. 2, mar.-abr. 1962, p. 14

A coluna vertical da cruz é formada pela coluna de fumaça de uma explosão de uma bomba nucelar, continuado acima da cruz pela parte redonda dessa explosão, formando em conjunto o caraterístico cogumelo nuclear, um ano depois da crise de Cuba com a sua ameaça de um conflito nuclear entre a Rússia e os Estados Unidos da América [do Norte]. Cristo é morto em solidariedade a todas as vítimas da guerra, e um sinal contra a loucura da 
sua mais nova vertente: a guerra nuclear. Uma pessoa rasga um cartaz com as palavras "Cristo é o Senhor" pela metade e começa a escrever com letras vermelhas "Revol[ução]". Isso ocorre enquanto um grupo de três pessoas está dormindo, ignorando o está acontecendo ao seu redor. Essa vez, porém, não se trata dos discípulos que abandonam o Cristo em seu sofrimento no jardim do Getsêmani, mas, de pessoas que ignoram o que está acontecendo no mundo e que inclusive, ameaça o anúncio do senhorio de Cristo. A colagem ao lado (figura 10) mostra os contrastes sociais estabelecidos na nova capital Brasília. Uma pessoa anda em frente aos novos prédios representativos com Cilindro e Caudas, enquanto os pobres vivem em casas pequenas superlotadas. A colagem ilustra um artigo com o título irônico "Brasil sem retoque para o brasileiro tranquilo” (TOLEDO, 03-04/1962, p. 14-16).

Figura 11: Capa da Cruz de Malta de setembro a outubro 1962

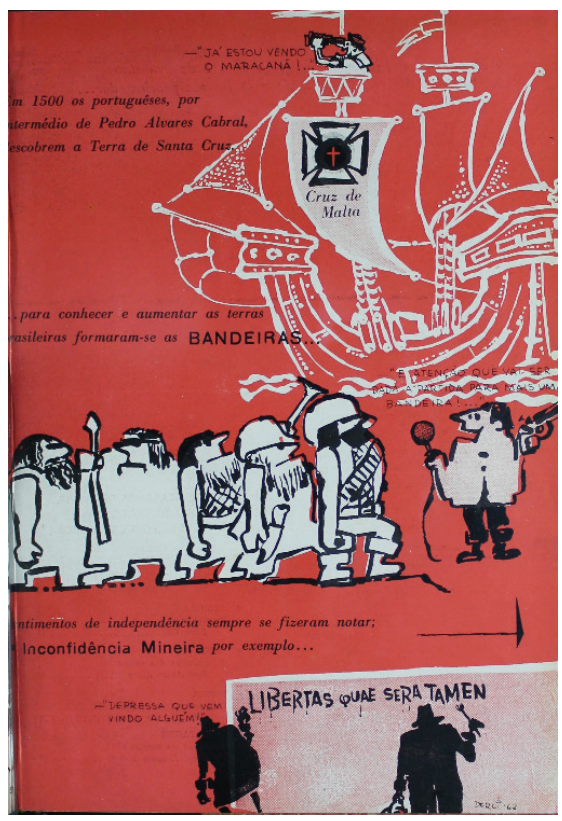

Fonte: CdM, ano 35, n. 4, set.-out. 1962, p. capa
Figura 12: Capa da Revista cruz de Malta de setembro a outubro 1962

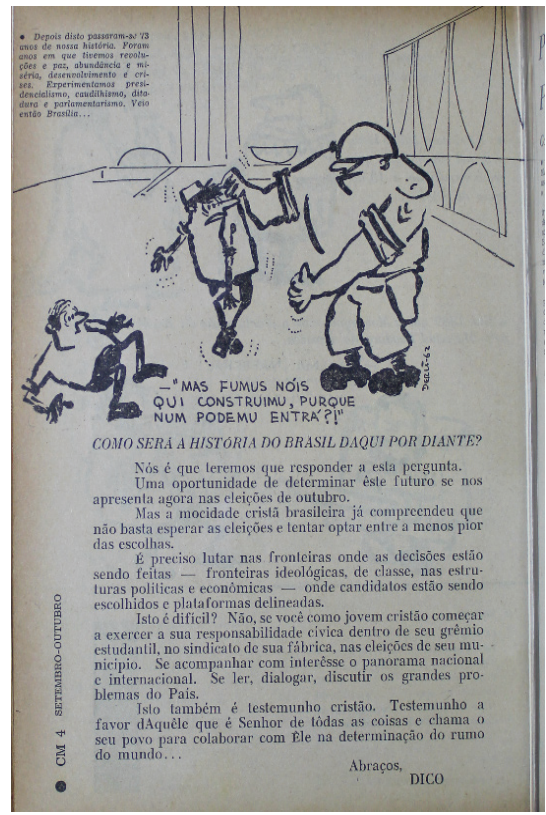

Fonte: CdM, ano 37, n. 4, set.-out. 1962, p. 4

Na edição setembro/outubro de 1962 cria-se uma narrativa de quatro páginas, incluindo a capa, da história do Brasil desde a "descoberta da Terra de Santa Cruz" até a construção de Brasília" sob a pergunta: "Como será a história do Brasil daqui por diante? (SCHISSLER, 1962, p. 4). Nessa breve história se refere à descoberta, aos bandeirantes, à Inconfidência Mineira, 
à Independência de 1812, à abolição de 1888, à proclamação da República até à construção de Brasília que excluiu os trabalhadores que a construíram. Segue como parte do editorial a afirmação do pastor "Dico" quanto às eleições de 1962:

Uma oportunidade de determinar este futuro se nos apresenta agora nas eleições de outubro. Mas a mocidade cristã brasileira já compreendeu que não basta esperar as eleições e tentar optar entre a menos pior das escolhas. É preciso lutar nas fronteiras onde as decisões estão sendo feitas - fronteiras ideológicas de classe, nas estruturas políticas e econômicas - onde candidatos estão sendo escolhidos e plataformas delineadas (SCHISSLER, 1962, p. 4).

Mais uma vez, lê-se o mundo, no caso, a narrativa que a nação brasileira apresenta em relação a si mesma. Essa narrativa é diversas vezes quebrada ironicamente, revelando as suas contradições, como fica evidente na última caricatura da p. 4 (figura 12). Aqui perguntam com sotaque nordestino os trabalhadores que criaram Brasília no momento que são expulsos da cidade: "Mas, fumus nois qui construimu. Purque num podemu entrá?" A nação de costas aos seus trabalhadores, urbanos e rurais, requer uma igreja cristã que assuma seu lugar ao lado deles.

Em 1964, meses depois do golpe militar que roubou da juventude militante até a palavra "revolução", aparecem novamente fotografias da juventude do seu cotidiano na igreja (figura 13), estudando, cantando a violão, em congressos, tomando a Santa Ceia e orando. Já a última capa do ano 1964 fecha com uma referência a um artista popular católico, Raimundo de Oliveira. Mais uma vez assume "Dico" o comando (figura 14). A sua entrevista descreve o trajeto do artista, seus contatos com protestantes, suas raízes populares e fecha com a pergunta: "Quando produzirá o protestantismo brasileiro um pintor de temas bíblicos da estatura artística de um Raimundo, mas, com ainda maior sensibilidade espiritual à mensagem total da Escritura?” (SCHISLER, $11-12 / 1964$, p. 13). ${ }^{18}$

18 O cruzamento do tema da cultura com o tema do compromisso social transparece também em seu artigo na revista Cruz de malta com o título "Como vai o seu Q.[Quociente] C[ultural].?” (SCHISLER, 1962, p. 14-18). Acréscimos no título pelo autor. 
Figura 13: Capa da Cruz de Malta de setembro a outubro 1964

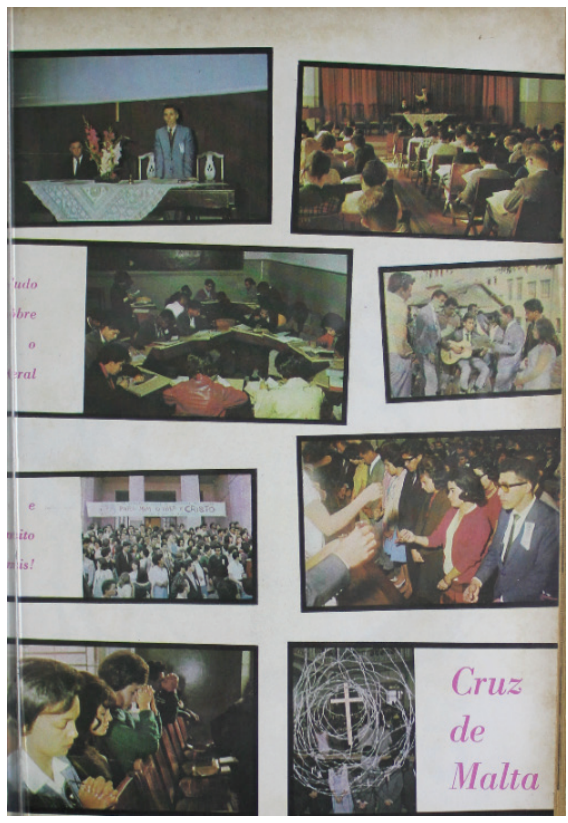

Fonte: CdM, ano 37, n. 4, set.-out. 1964, p. capa
Figura 14: Capa da Revista cruz de Malta, de novembro a dezembro 1964

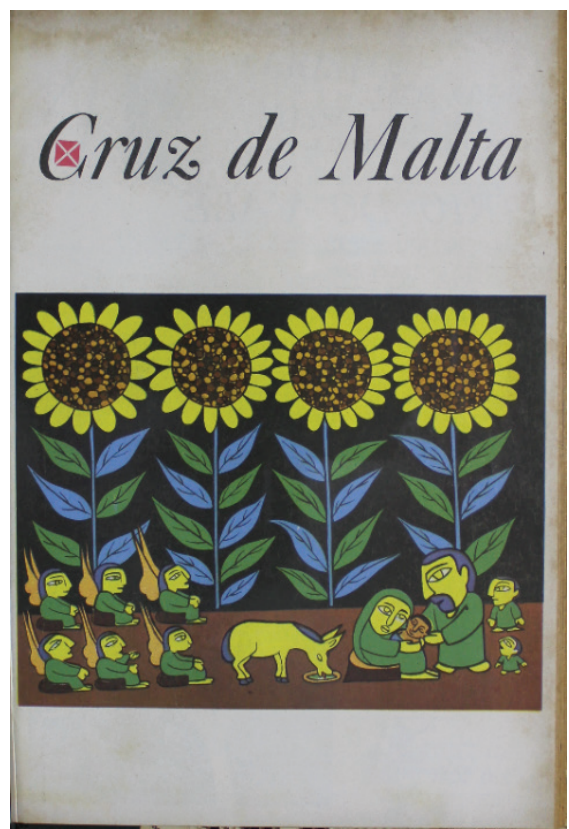

Fonte: CdM, ano 37, n. 5, nov.-dez. 1964, p. capa

Com essa pergunta, que parece ecoar a pergunta de Gilberto Freire de 1962, finalizamos a breve apresentação das capas da revista Cruz de Malta.

\section{Uma linguagem religiosa visual de vanguarda em prol de uma espiritualidade militante}

Tentamos comprovar a hipótese que parte da juventude protestante, aqui representada por uma equipe redacional de uma revista atuando nos anos 1962/1963, procurava uma nova linguagem artística capaz de articular entre sua geração um projeto de cristianismo engajado, um cristianismo em prol do desenvolvimento do país brasileiro, com o olho nos mais vulneráveis e excluídos.

A esse anseio correspondeu um estilo artístico que retrata, preferencialmente, a realidade brasileira. Esta perspectiva transparece em diversos momentos, por exemplo, na apreciação da equipe redacional do novo cinema brasileiro:

[...] o Cinema Novo. Um cinema sério que - bem ao contrário das centenas de chanchadas completamente desvinculadas da realidade brasileira - está inteiramente voltado aos nossos problemas. É um cinema engajado [...] o Cinema Novo é a busca desesperada duma saída para o nosso subdesenvolvimento (GUARABI; TOLEDO, 07-08/1962, p. 24). 
Essa narrativa artística "inteiramente voltada aos nossos problemas", uma arte engajada, segue à tradição do realismo brasileiro que se iniciou no campo da literatura, nas obras tardias de Machado de Assis ao redor de 1880. Quanto ao estilo, usa-se uma estética gráfica que vem mais do campo da comunicação e do desenho gráfico cuja narrativa é mais contemporânea. Em serviço e à procura do bem comum, "vinculada com a[s] realidade[s] brasileira[s]", em perspectiva religiosa, articula-se dentro das linguagens do desenho gráfico.

Figura 15: Ruedi Kulling, Cartaz para canetas BIC, 1962

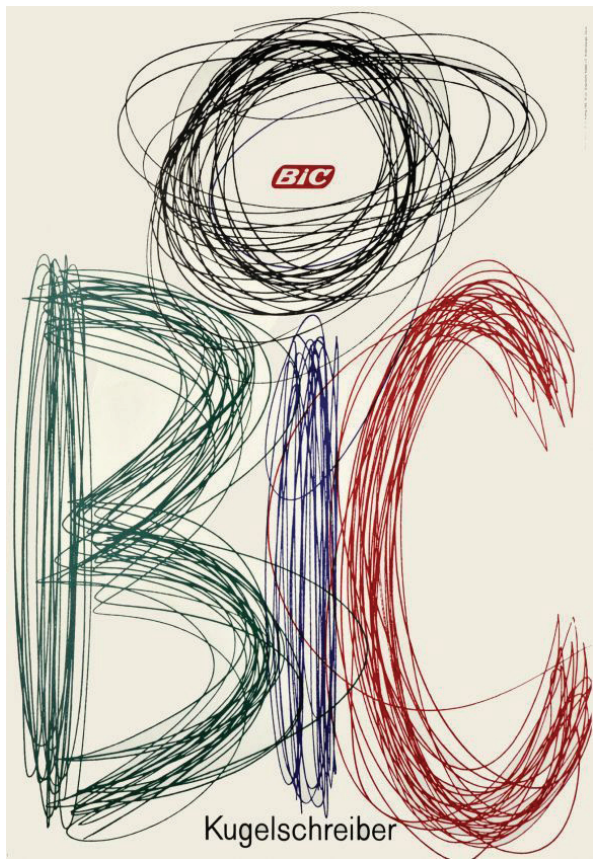

Fonte: www. Pinterest.org
Figura 16: Haertfield, John. Come and see Gemrany,1936

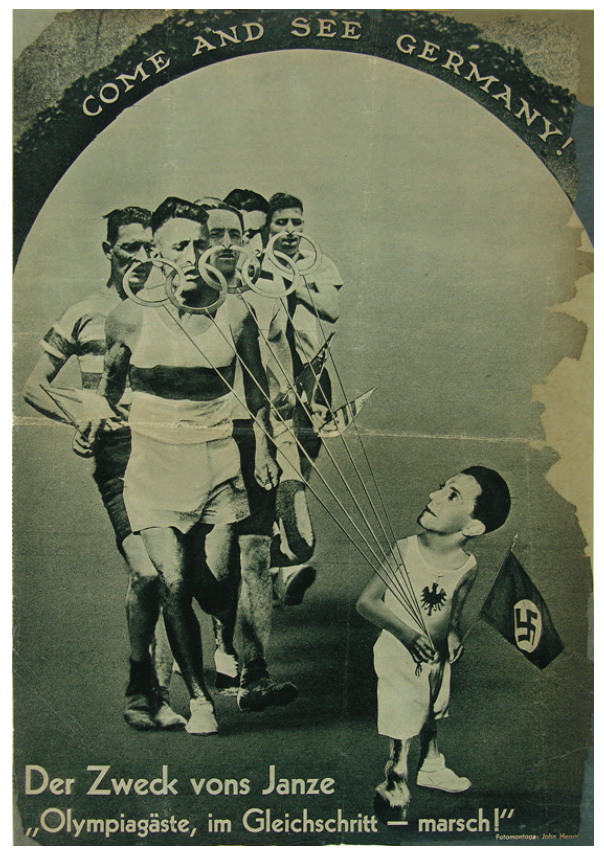

Fonte: https://akronartmuseum.org

As capas lembram cartazes, e seu estilo inclua desenhos com a ponta dura de canetas. Essa dureza das linhas que se opõe a uma estética do belo e agradável, mas, favorece um estilo documental um registro social não descaracterizado pela estética do belo. Com isso, eles também visualizam uma estética diferenciada relativo à cruz ou à crucificação, mais próxima aos crucifixos da época da peste bubônica ou no Retábulo de Isenheim pintado por Matthias Grünewald. O realismo dessa tradição abandona o clássico caminho da estética como beleza no sentido de um retrato agradável, e substitui-a por uma estética mais "realista", aberto para a articulação tanto do povo como 
de Cristo, do seu sofrimento solidário, do sofrimento que levou em última consequência até a sua morte, até a sua morte na cruz: o Cristo abandonado por muitos, entretanto, esses muitos jamais abandonados por Ele.

Outro tipo para articular também esse realismo [religioso], é o estilo do desenho gráfico em forma de colagem. Uma das referências é certamente John Heartfield ${ }^{19}$ (figuras 10 e 16).

Foto 17: Igreja Metodista de Sorocaba, SP

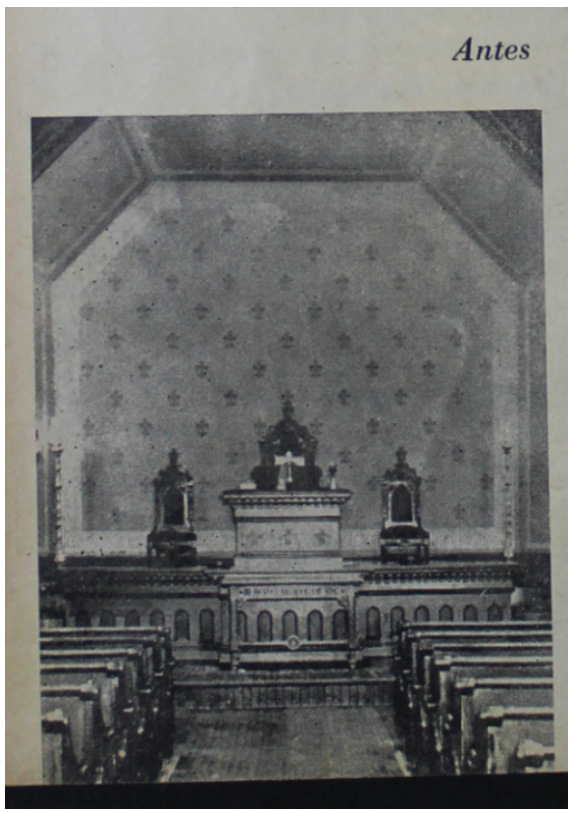

Foto 18: Igreja Metodista de Sorocaba, SP

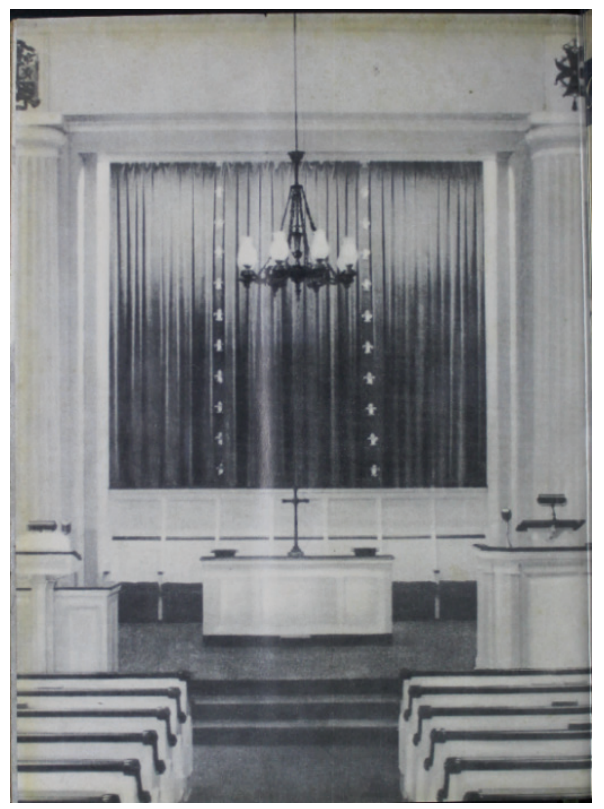

Fonte: Cruz de Malta, ano 34, n. 2, p. 4 (fev. 1961) Fonte: Cruz de Malta, ano 33, n. 11, p. 2 (nov. 1960)

Como o tema dessa publicação trata também da liturgia, gostaríamos ainda de estabelecer uma relação com uma revolução que ocorreu na época no espaço reservado nas comunidades metodistas para o culto (figuras $17 \mathrm{e}$ 18). ${ }^{20}$ À discussão da abertura externa da igreja em prol do bem comum na sociedade, correspondia um movimento interno na igreja de uma ressignificação do espaço ao redor da mesa do Senhor em relação à nave da igreja. A derrubada da grade como divisora entre santuário e nave para sinalizar

19 John Heartfield era o pseudônimo de Helmut Herzfelde (1891-1968).

20 As observações a respeito das mudanças dos espaços internos das igrejas locais devemos aos estudos de Ana Lídia Albuquerque desenvolvidos em sua dissertação "Política, Poética e Performance no Espaço Religioso: estudo da cultura material da Igreja Metodista Central em Santo André”, defendida em Outubro 2018. Nos somente estabelecemos uma relação entre suas respectivas observações e o nosso tema. 
espacialmente a graça de Deus como incondicional e universal e a instalação de um púlpito para leituras leigas ao lado do púlpito comum para sinalizar a importância do sacerdócio comum anunciaram juntos uma abertura da igreja para um novo tempo. O que nos parece hoje comum e o padrão do espaço litúrgico, era na época considerado uma revolução, como um leitor da revista Cruz de Malta afirmava:

\section{A arquitetura de nossos templos em revolução}

FIQUEI DEVERAS IMPRESIONADO com o artigo de Enzo Ceccon, na revista de novembro, a respeito da revolução arquitetônica que se processa em nossos templos, com a volta da centralidade da mesa de comunhão (ou altar) [...]

Agora, o que mais me impressionou foram as contra-capas. Achei aqueles interiores belísismos. Inspiram reverência [...] O que achei interessante foi o contraste entre o antes e o depois [...] A modificação é impressionente! Posso imaginar o efeito que teria em minha igreja local tal modificação. Mas, para isto, será preciso mudar toda uma mentalidade. E isto não será fácil. Mas rogamos que Deus use a CRUZ DE MALTA para liderar esta revolução tão importante. [...]

- Publicamos ao lado, [...] uma reprodução do antes e depois das nossas duas contra-capas de novembro. O contraste torna-se agora ainda mais claro, não? (CRUZ DE MALTA, 2, fev. 1961, p. 4).

Enquanto a revolução "nos" templos da Igreja Metodista avançou ao longo das próximas décadas, até se tornar padrão a partir de 1980/1985, a revolução na cultura visual não voltou mais dessa forma.

\section{Considerações finais}

As capas da revista Cruz de Malta do ano de 1962, de Derli Barroso, apresentam tanto em relação aos aspectos formais ou estilísticos como aos conteúdos articulados, uma linguagem visual religiosa sem precedentes na cultura visual evangélica brasileira. Seu aparecimento e desparecimento marcam um momento curto na história do protestantismo brasileiro de missão quando a juventude militante e a igreja não se entenderam como uma contradição em si, mas, uma opção, procurada e defendida por um segmento da igreja na igreja. Não se chegou nesse momento de repetente, nem se perdeu esse momento de uma noite para a outra. Mas, se a introdução dessa linguagem visual anuncia a possibilidade e desejo de que a juventude militante e a igreja andem juntas, o abandono dessa linguagem visual parece na retrospectiva também o pré-anuncio que se chegou na época a um impasse que, na sua última análise, preferia sacrificar a juventude militante em lugar de radicalização da igreja ao redor das causas em comum. A busca da juventude por uma linguagem artística nova, 
capaz de articular um momento novo em reação à sociedade e seu desejo de viver isso a partir das suas convicções religiosas não se realizou dentro e com a igreja. E eventualmente sinaliza justamente a diacronia entre o começo da abertura interna da igreja pela reorganização do espaço interior das igrejas a partir do fim da década de 1950 e a vanguarda da cultura visual da mocidade, que essa mocidade ainda não cabia dentro da igreja...

Entretanto, não foi a última vez que novas narrativas visuais iriam articular novos projetos dentro das igrejas cristãs. De fato, estamos em meio de uma nova e imensa revolução cultural e religiosa, que sua vez se apresenta por cartazes, páginas na internet, etc. etc. Fica para outros estudos a tarefa de apresentar e analisar essas novas narrativas visuais religiosas e analisar a relação entre projetos gráficos, visões do mundo e reflexos nas liturgias das igrejas.

\section{Referências bibliográficas}

ARAÚJO, João Dias de. Mãos vazias; Nordeste; sem fim. Cruz de Malta, ano 35, n. 4, p. 26-27, set./out. 1962.

ARAÚJO, João Dias de. Inquisição sem fogueiras: a história sombria da Igreja Presbiteriana do Brasil. 3. ed. São Paulo: Fonte Editorial, 2010. 222 p [1 ${ }^{\text {a }}$ ed. 1982, ISER].

BEULKE, Dorival. A grande fogueira. Cruz de Malta, ano 35, n. 1, p. 16-18, jan./fev. 1962.

CECCON, Clandius Silvius Petrus. 10 coisas sobre os direitos dos trabalbadores. Petrópolis: Vozes, 1985.

CECCON, Claudius Silvius Petrus. A vida na escola e a escola na vida. 43. ed. Petrópolis: Editora Vozes; IDAC, 2013 [1 ${ }^{\mathrm{a}}$ ed.1990].

CECCON, Claudius Silvius Petrus. Enciclopédia Itaú Cultural de Arte e Cultura Brasileiras. São Paulo: Itaú Cultural, 2018. Disponível em: <http://enciclopedia.itaucultural.org.br/ pessoa14876/claudius >. Acesso em: 07 de set. 2018.

CECCON, Claudius Silvius Petrus; EDNIR, Madza. Caminhos para elaborar uma proposta de Educação Integral em Jornada Ampliada. Brasília: MEC, 2011.

CECCON, Claudius Silvius Petrus; FREIRE, Paulo. El grito manso / The Meek Cry. Madri: Siglo XXI Ediciones, 2004.

DERLI Barroso. Enciclopédia Itaú Cultural de Arte e Cultura Brasileiras. São Paulo: Itaú Cultural, 2018. Disponível em: < http://enciclopedia.itaucultural.org.br/ pessoa3515/derli-barroso>. Acesso em: 07 de Set. 2018. Verbete da Enciclopédia.

DERLY Marques. Anti-comunismo: na fonte de inspiração para pastores sem assunto. Expositor Cristão, ano 77, n. 20, p. 2, 15. out. 1962.

DERLY Marques. Enciclopédia Itaú Cultural de Arte e Cultura Brasileiras. São Paulo: Itaú Cultural, 2018. Disponível em: < http://enciclopedia.itaucultural.org.br/ pessoa403533/derly-marques>. Acesso em: 07 de set. 2018.

FREIRE, Gilberto. A tarefa do artista é servir. In: CONFEDERAÇÃO EVANGÉLICA DO BRASIL. Cristo e o processo revolucionário brasileiro: Conferência do Nordeste. IV Reunião de Estudos. Rio de Janeiro: Loquib, 1963, p. 59-60. 
GUARABI, Heleny. In: Enciclopédia Itaú Cultural de Arte e Cultura Brasileiras. São Paulo: Itaú Cultural, 2018. Disponível em: < http://enciclopedia.itaucultural.org.br/ pessoa405346/ heleny-guariba>. Acesso em: 07 de Set. 2018. Verbete da Enciclopédia.

GUARABI, Heleny; TOLEDO, Caio. O pregador é "protestante". Cruz de Malta, ano 35, n. 3, p. 23-25, jul.-ago. 1962.

HEARTFIELD, John. Colagem "Come and see Germany". Arbeiter-Illustrierte-Zeitung, vol. 15, n. 27, p. 432, jul. 1936.

RENDERS, Helmut. Uma proposta de periodização da cultura visual evangélica brasileira: surgimento, abrasileiramento e metaformização glocal. [Dossiê Cultura Visual]. Numen, vol. 21, n. 1, p. 10-37, jan.-jun. 2018.

S. N. Fronteira cultural. In: CONFEDERAÇÃO EVANGÉLICA DO BRASIL. Cristo e o processo revolucionário brasileiro: Conferência do Nordeste. IV Reunião de Estudos. Rio de Janeiro: Loqui, 1963, p. 182.

SANTOS, Almir dos. Set. 1960, A fronteira cristã dos nossos dias. Cruz de Malta, ano 33, n. 1, p. 14-18, jan.-fev. 1960.

SCHISLER FILHO, William R. Como vai o seu Q. C.?. Cruz de Malta, ano 35, n. 4, p. 1418, set.-out. 1962.

SCHISLER FILHO, William R. "Natal é tristeza para Raimundo". In: Cruz de Malta, ano 37, n. 5, p. 10-13 (nov./dez. 1964).

SHAUL, Richard. O que é mesmo que Cristo pode fazer por nós?... Cruz de Malta, ano 34, n. 1, p. 9-12, jan. 1961.

SHAUL, Richard. O cristão na esquerda. Cruz de Malta, ano 35, n. 2, p. 26-32, mar.-abril 1962.

SHAUL, Richard. O cristão no momento revolucionário de hoje. Cruz de Malta, ano 35, n. 5, p. 22-26, maio-jun. 1962.

S.N. Gilberto Freire falha aos evangélicos. Expositor Cristão, ano 78, n. 8, 1, p. 3, 05-04, 1963.

TOLEDO, Caio Navarro de. Brasil sem retoques para o brasileiro tranquilo. Cruz de Malta, p. 14-16, mar.-abr. 1962.

TOLEDO, Caio Navarro de. O governo Goulart e o golpe de 64. São Paulo: Brasiliense, 1984.

TOLEDO, Caio Navarro de (Org.). 1964 visões críticas do golpe: democracia e reformas no populismo. 2. ed. Campinas: Unicamp, 2014.

Submetido em: 3-3-2019

Aceito em: 11-6-2019 